\title{
Reterogasserian anhydrous glycerol injection therapy in trigeminal neuralgia: observations in 552 patients
}

\author{
S S SAINI \\ From the Neuro Sciences Centre, All India Institute of Medical Sciences, New Delhi, India
}

SUMMARY Five hundred and fifty two patients with trigeminal neuralgia were treated with reterogasserian anhydrous glycerol injections. Two hundred and twenty four patients $(59 \cdot 1 \%)$ at the end of two years and eight patients $(8 \cdot 1 \%)$ at the end of six years were free from pain after a single injection. There was recurrence of pain in 136 patients $(27.7 \%)$ after one year and in an additional 155 patients $(40.9 \%)$ after two years. The recurrence was seen earlier in patients who had either a neurolytic injection or had undergone surgical procedures, compared with those patients who had been treated with drugs. Complications of injection were few and not incapacitating. The technique was found to be safe, cheap and effective in treating trigeminal neuralgia, and is recommended for centres where there are financial constraints.

The treatment of trigeminal neuralgia has intrigued the minds and ingenuity of physicians for a long time. Failure of medical management led to injection of the sensory root with neurolytic agents and ultimately surgical rhizotomy. Controlled partial thermocoagulation of the trigeminal ganglion, developed by Sweet and Wepsic ${ }^{1}$ and Schurmann et al $^{2}$ has also been found to be a very effective and safe technique (Menzel $e t a l^{3}$ and Nugent $e t a l^{4}$ ). Radiofrequency coagulation, however, requires expensive equipment and a brief period of anaesthesia at the time of making a lesion.

Anhydrous glycerol injection into the trigeminal cistern was found to alleviate the neuralgic pain by Hakanson. ${ }^{56}$ Since then experience with the use of glycerol has been reported by Saini, ${ }^{7}$ Lunsford and Bennett, ${ }^{8}$ Sweet et al, ${ }^{9}$ Arias ${ }^{10}$ and Beck et al. ${ }^{11}$

The present series comprised of 552 consecutive patients with trigeminal neuralgia treated with percutaneous reterogasserian glycerol injection into the trigeminal cistern and is the largest reported so far. These patients were seen during the period from March 1979, to August 1986 at the Pain Clinic of The All India Institute of Medical Sciences, New Delhi.

\section{Method}

Anhydrous glycerol was prepared according to the method described $\left(\right.$ Saini $\left.^{7}\right)$. Glycerol $(0 \cdot 2-0 \cdot 3 \mathrm{ml})$ was injected

Address for reprint requests: Prof SS Saini, Neurosciences Centre, AIIMS, New Delhi 110029, India.

Received 24 February 1987 and in revised form 26 March 1987. Accepted 22 May 1987 through a 22 gauge spinal needle into the trigeminal cistern in the sitting position with neck slightly flexed. Radiological control using a C-arm image intensifier with a two frame memory was used to confirm position of the needle tip. The position of the head was maintained for at least 1 hour, after which the patient was sent home. Glycerol was not withdrawn after its injection into the trigeminal cistern in any patient. Patients were followed up 48 hours later and subsequently at intervals of 3-6 months.

\section{Case materials}

All the patients were referred by either neurologists or neurosurgeons after careful clinical evaluation. However, CT was not done in every case. The majority of the patients presented in the 3 rd to 5 th decades of life. There was male preponderance and the involvement was commoner on the right side of the face (table 1). Therapy given before the injection of anhydrous glycerol is listed in table 2 .

\section{Results}

Four hundred and sixty nine patients were followed regularly for periods ranging from 1 to 6 years. Eighty three patients were lost to follow up and were excluded from the analysis. Two hundred and twenty four patients $(59 \cdot 1 \%)$ at the end of two years and 29 patients $(17.4 \%)$ at the end of 5 years were symptom free (table 3). For patients with recurrence of symptoms, injection with anhydrous glycerol was repeated, and up to three injections were tried before the patient was treated with radiofrequency coagulation. A total of 18 patients $(3.8 \%)$ only who had partial or no relief, were treated with radiofrequency coagulation. It was observed that the recurrence of pain was earlier 
Table 1 Age, sex and pain distribution

\begin{tabular}{lc}
\hline Age in $r$ & No of parients \\
\hline $20-30$ & 26 \\
$31-40$ & 104 \\
$41-50$ & 210 \\
5160 & 96 \\
$61+$ & 116 \\
Male Female & 364188 \\
Right Left & 368184 \\
\hline
\end{tabular}

if either the glycerol was not freshly prepared or the patient had been injected with alcohol or phenol or had undergone radiofrequency coagulation and/or surgical rhizotomy earlier. The frequency of recurrence in previously untreated patients was much lower than in other patients (table 4). Recurrence within 1 year was seen in only $3.4 \%$ previously untreated patients as compared with $24.3 \%$ in the neurolytic/surgical intervention group. Eight patients in the previously untreated group were found to be pain free 6 years after a single injection of anhydrous glycerol.

Dysaesthesia was complained of in 61 patients and 26 patients developed anaesthesia delorosa. The latter complication was seen only in patients who had received either a neurolytic injection or had undergone surgical intervention prior to the use of anhydrous glycerol. Sixteen patients developed paresis of the motor component of V3 which recovered completely within 3-4 months. Impairment of corneal reflex and keratitis was recorded in 23 patients. No patient in the previously untreated group developed dense facial anaesthesia. However, a feeling of heav-

Table 2 Therapy prior to glycerol injection

\begin{tabular}{ll}
\hline Therapy & No of patients \\
\hline Carbamazepine diphenyl hydantion & 232 \\
Alcohol phenol single injection & 136 \\
multiple injection & 166 \\
Radiofrequency coagulations & 12 \\
Surgical rhizotomy & 6 \\
\hline
\end{tabular}

Table 3 Follow up and recurrence after single injection of anhydrous glicerol

\begin{tabular}{|c|c|c|c|}
\hline Duration of follow up & $\begin{array}{l}\text { No of } \\
\text { patients }\end{array}$ & $\begin{array}{l}\text { No with } \\
\text { recurrence }\end{array}$ & $\%$ \\
\hline $\begin{array}{c}\text { Upto l yr } \\
. \quad 2 y r \\
. \quad 3 y r \\
. \quad 4 y r \\
. \quad 5 y r \\
. \quad 6 y r\end{array}$ & $\begin{array}{r}469 \\
379 \\
306 \\
244 \\
166 \\
98\end{array}$ & $\begin{array}{l}130 \\
155 \\
208 \\
137 \\
137 \\
90\end{array}$ & $\begin{array}{l}27.7 \\
40.9 \\
67.9 \\
56.1 \\
82.5 \\
91.8\end{array}$ \\
\hline
\end{tabular}

Not included are 8.3 patients which were lost to follow up.
Table 4 Recurrence of neuralgia in treated and previously untreated patients

\begin{tabular}{|c|c|c|}
\hline Period of follow up & $\begin{array}{l}\text { Neurolytic/surgical } \\
(266)\end{array}$ & $\begin{array}{l}C A R B D P H \\
(203)\end{array}$ \\
\hline $\begin{array}{cc}\text { Up to } & 1 \mathrm{yr} \\
. . & 2 \mathrm{yr} \\
. . & 3 \mathrm{yr} \\
. & 4 \mathrm{yr} \\
. . & 5 \mathrm{yr} \\
. . & 6 \mathrm{yr}\end{array}$ & $\begin{array}{r}114(24 \cdot 3 \%) \\
96(25 \cdot 3 \%) \\
168(54 \cdot 9 \%) \\
118(48 \cdot 3 \%) \\
122(73 \cdot 4 \%) \\
90(91 \cdot 8 \%)\end{array}$ & $\begin{array}{l}16(3.4 \%) \\
59(15.5 \%) \\
40(13.0 \%) \\
19(7.7 \%) \\
15(9.0 \%)\end{array}$ \\
\hline Lost to follow up & 54 & 29 \\
\hline
\end{tabular}

CARB: Carbamazepine: DPH: Diphenylhydantion.

iness was complained of by most patients. Appreciation of sensation to pin prick was preserved in all these patients. Fifteen patients developed herpes simplex in the distribution of the 2 nd and 3 rd divisions which cleared up within 7-10 days (table 5). No cranial nerve palsies were noted in any of the patients.

\section{Discussion}

Trigeminal neuralgia seems to be associated with structural abnormalities encroaching upon the trigeminal nerve, Gasserian ganglion or the root entry zone (Calvin et al $^{12}$ ). Jannetta ${ }^{13}$ attributed it to vascular compression by arterial loops but occasionally by veins. He has shown good results by microvascular decompression technique. However, this technique is a major surgical procedure and a number of cases develop recurrence. The typical features of trigeminal neuralgia have been explained by Loeser $e t a l^{14}$ on the basis of their theory of presynaptic inhibition and reflection sites duc to focal changes in the axon diameter or myelination. Presynaptic depolarisation can produce generation of an antidromic impulse and relcase of neurotransmitter at the A-delta synapse thus leading to pain perception. It is also believed that the attack could be terminated by depletion of the transmitter at the axo-axonic synapse.

It is not clear how anhydrous glycerol acts to relieve the neuralgic attacks, without producing the dense anaesthesia which is seen after neurolytic injections. ${ }^{15}$ But altered sensation in the form of paraesthesia or partial sensory loss, sluggish corneal reflex and temporary paresis of the V 3 motor component in some of the patients have been observed in the present

\section{Table 5 Complications}

Dysaesthesiae

Anaesthesia delorosa

V3 motor paresis

Keratitis

Herpes simplex 
series. This finding is consistent with those of Lunsford $e t a l^{8}$ and Beck et al. ${ }^{11}$ This slight degree of sensory loss has been well tolerated by the patients in this series. If the theory of the pain mechanism in trigeminal neuralgia as proposed by Calvin et al ${ }^{12}$ and pathophysiological changes described by Loeser et al $^{14}$ were true, one could presume that anhydrous glycerol probably insulates the so called pathological site on the axonas it has a high dielectric constant $\left(45.5\right.$ at $\left.25^{\circ} \mathrm{C}\right)$ making it a poor conductor. This would prevent the impulse reflection and presynaptic inhibition.

One hundred and thirty patients in the present series were below 40 years of age. This is at variance with the other reported series from the western countries. It is quite common to see patients suffering from trigeminal neuralgia below the age of 40 years in India. A similar age incidence has been reported by Rao, Dinakar, ${ }^{16}$ and Abraham and Chandy. ${ }^{17}$

The male preponderance may be because a larger number of male than female patients seek medical aid in India. Kalyanaraman and Ramamurthy ${ }^{18}$ reported $75 \%$ of male patients compared with $25 \%$ females suffering from trigeminal neuralgia in their series of 700 patients seen over a period of 20 years.

Complications like dysaesthesia in $4.9 \%$, temporary V3 motor paresis in $3.4 \%$ and herpes simplex in $3.1 \%$ patients were not incapacitating and were managed conservatively. However, 26 patients who developed anaesthesia delorosa complained of discomfort requiring the use of antidepressents and sedatives.

Although the recurrence rate is high compared with reported series using other treatment modalities, it is felt that this technique is simple, cost effective and has a low incidence of complications. It is certainly the technique most applicable to third world countries where the drug treatment is very expensive, the facilities for radiofrequency coagulation or microvascular decompression are available in only a few centres and the number of patients is enormous. Further experimental studies are required to ascertain the exact mode of action of glycerol.

\section{References}

1 Sweet WH, Wepsic JG. Controlled thermo-coagulation of trigeminal ganglion and rootlets for differential destruction of pain fibres. Part I, Trigeminal neuralgia. J Neurosurg 1974;40:143-56.
2 Schurmann $\mathbf{M}$, Butz $\mathbf{M}$, Broack $\mathbf{M}$. Temporal reterogasserian resection of trigeminal root versus controlled elective percutaneous electro coagulation of the ganglion of Gasser in the treatment of trigeminal neuralgia. Acta Neurochir (Pain) 1972;26:33-53.

3 Menzel J, Pitrowski W, Penzholz H. Long term results of gasserian ganglion electro coagulation. $J$ Neurosurg 1975;42:140-3.

4 Nugent GR, Berry B. Trigeminal neuralgia treated by differential percutaneous radio frequency coagulation of the gasserian ganglion. $J$ Neurosurg 1974;40: 517-23.

5 Hakanson S. Reterogasserian glycerol injection as a treatment of tic douloureux. Adv Pain Res Ther. (Proceedings of the Third World Congress on Pain). New York: Raven Press, 1983:927-33.

6 Hakanson S. Trigeminal neuralgia treated by the injection of glycerol into trigeminal cistern. Neurosurgery 1981;9:38-46.

7 Saini SS. Injection treatment of trigeminal neuralgia with special reference to the use of anhydrous glycerol. Neurology India 1981;29:31-34.

8 Lunsford LD, Bennett MH. Percutaneous reterogasserian glycerol rhizotomy for tic douloureux. Part I Technique and results in 112 patients. Neurosurgery 1984;14:424-30.

9 Sweet WH, Poletti CE, Macon JB. Treatment of trigeminal neuralgia and other facial pain by retrogasserian injection of glycerol. Neurosurgery 1981;9:647-53.

10 Arias MJ. Percutaneous reterogasserian glycerol rhizotomy for trigeminal neuralgia. A prospective study of 100 cases. J Neurosurg 1984;65:32-36.

11 Beck DW, Jaffrey JO, Urig EJ. Percutaneous reterogasserian glycerol rhizotomy for treatment of trigeminal neuralgia. $J$ Neurosurg 1986;65:28-31.

12 Calvin WH, Loeser JD, Howe JF. A neurophysiological theory for the pain mechanism of tic douloureux. Pain 1977;3:147-54.

13 Jannetta PJ. Treatment of trigeminal neuralgia by sub occipital and transtentorial cranial operations. Clinical Neurosurgery. Baltimore: The Williams and Wilkins Co, 1977:538-49.

14 Loeser JD, Calvin WH, Howe JF. Pathophysiology of trigeminal neuralgia. Clinical Neurosurgery. Baltimore: The Williams and Wilkins Co, 1977:527-37.

15 Lunsford LD, Bennett MH, Martinez AJ. Experimental trigeminal glycerol injection, electrophysiologic and morphologic effects. Arch Neurol 1985;42:146-9.

16 Rao SB, Dinakar I, Trigeminal neuralgia. Neurology India 1970;18:181-4.

17 Abraham J, Chandy J. Trigeminal neuralgia. Neurology India 1962;10:59-61.

18 Kalyanaraman S, Ramamurthi B. Trigeminal neuralgia. Neurology India 1970;18 Suppl:100-8. 